“(C) 2019 IEEE. Personal use of this material is permitted. Permission from IEEE must be obtained for all other uses, in any current or future media, including reprinting/republishing this material for advertising or promotional purposes, creating new collective works, for resale or redistribution to servers or lists, or reuse of any copyrighted component of this work in other works." 


\title{
A Bibliometric Analysis of Technology Management Research at PICMET for 2009-2018
}

\author{
Cetindamar, D. ${ }^{1}$, Kocaoglu, D. ${ }^{2}$, Lammers, T. ${ }^{1}$, and Merigo, J. M. ${ }^{1,3}$ \\ ${ }^{1}$ School of Information, Systems and Modelling, Faculty of Engineering and Information Technology, University of Technology \\ Sydney, Sydney, Australia. \\ ${ }^{2}$ Engineering and Technology Management Department, Portland State University, Portland, OR, USA. \\ ${ }^{3}$ Dep. of Management Control and Information Systems, School of Economics and Business, University of Chile, Santiago, Chile.
}

\begin{abstract}
-
The Portland International Centre for Management of Engineering and Technology (PICMET), was established in 1989. It has since become one of the leading organizations in the field of management of engineering and technology in the world. PICMET provides a strong platform for academicians, industry professionals and government representatives to exchange new knowledge derived from both research and implementation of technology management. To celebrate its 30-year journey, and to show the trends in technology management research and implementation over the past ten years (2009-2018), this paper develops a bibliometric analysis of the more than 3000 papers accepted for inclusion in PICMET conferences. The study highlights the topics, authors, journals and countries where significant research on technology management is conducted.
\end{abstract}

\section{INTRODUCTION}

The Technology Management (TM) discipline has a history of almost 65 years, as indicated in the special issue of IEEE Transactions on Engineering Management in 2004 [1]. TM has become an even more self-sustained discipline in the last 30 years with the emergence of specialized professional organizations, in particular PICMET (Portland International Center for Management of Engineering and Technology) [2].

The analysis of a body of knowledge offers many advantages: showing trends in the field, pointing out the main knowledge generators (i.e. key institutions and authors), and highlighting emerging topics in a field [3]. In general, mining, bibliometric and other techniques are applied to journals to find out the developments in the TM field [3, 4].

Conducting such a research intelligence activity for conferences might be beneficial to understand the platforms serving to academicians developing knowledge that are ultimately published in journals. In fact, there has been three separate papers examining PICMET papers covering different time frames: the period of 1997-2003 [5], the period of 19972008 [6]; and the period of 2001-11 [7].

The present study follows the tradition and aims to cover the last decade: 2007-2018. We will present our findings regarding authors, institutions and topics covered in PICMET papers like the previous articles have done. Then, this study will make comparisons with the previous studies to highlight some key changes that might show the historical evolution of PICMET. But in addition to the traditional analysis, our paper will uniquely present a citation network analysis based on the references used in PICMET papers that will highlight the body of knowledge feeding the PICMET attendees.

\section{METHODOLOGY}

Bibliometrics is a research field of information and library sciences that studies the bibliographic data with quantitative methods [8,9]. Due to the development of computers and internet [10], bibliometrics has become a very practical approach to analyse scholarly research because it provides a comprehensive overview of the leading trends occurring in the academic community $[11,12]$.

In order to develop a bibliometric analysis, it is important to define and select the bibliometric indicators that will explain the results $[13,14,15]$. This paper considers the number of publications and citations. Note that the number of publications is used to measure productivity and the most productive authors while the number of citations measures popularity and influence $[16,17]$.

The focus of this work consists in presenting a graphical mapping of the bibliographic data [18]. To do so, the article uses the visualization of similarities (VOS) viewer software [19]. VOS viewer is a computer software that collects the bibliographic data and builds maps according to different bibliometric techniques including co-citation [20], bibliographic coupling [21], and co-occurrence of keywords [22]. Recall that graphical maps with co-citation [23], measure the most cited actors (size of the circles) and those that receive most frequently citations from the same sources. Graphs with bibliographic coupling [24], analyse the actors with the highest number of publications (size of the circles) and those that cite most frequently the same sources. Maps with cooccurrence of keywords, measure the most popular keywords (size of the circles) and those keywords that appear most frequently in the same papers [25].

\section{DATA ANALYSIS}

This paper uses the Scopus database to analyse the bibliographic information of the publications in PICMET conferences. The focus is on the publications available in Scopus from conferences held between 2009 and 2018. Thus, 
the analysis tries to provide a general overview of the leading trends in the conference during the last ten years. The search process uses different keywords of PICMET including the full and abbreviated name. Next, the search filters the results to consider only those between 2009 and 2018. The final result identifies 3012 papers published in 10 PICMET conferences between 2009 and 2018 (1594 for 2009-2013 and 1418 for 2014-2018). This number is slightly lower than the 3383 papers published during for PICMET in the eight conferences that took place during the $1997-2008$ period [6]

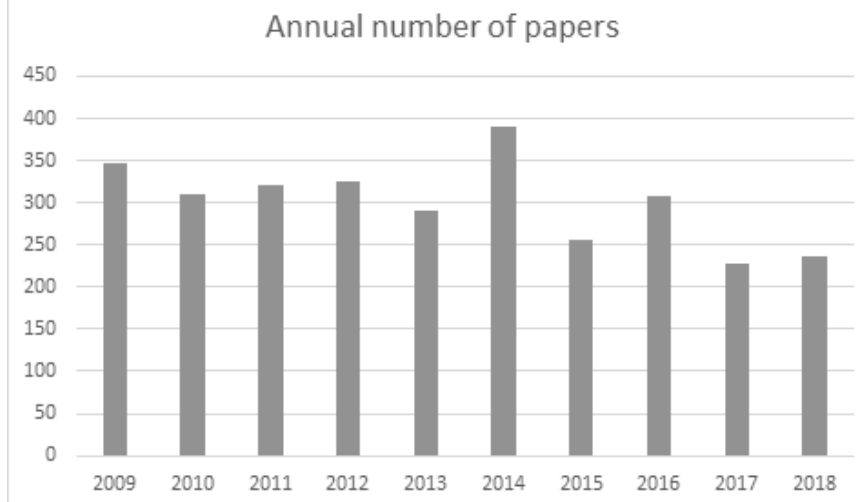

FIGURE I: ANNUAL NUMBER OF PAPERS PUBLISHED IN PICMET CONFERENCES

By 2009, PICMET had already been established as a leading conference in the field for quite some time. This is reflected in the high annual number of publications. This number remained rather stable between 300 and 350 for 20092012. In 2013, the number of publications dropped below the 300 mark before jumping to almost 400 in 2014. From 2015 onwards, there has been a slight decline in the number of publications to around the 250 mark. Figure I visualizes the annual number of articles published in PICMET for the last 10 years. Analyses of the co-occurrence of keywords and the cocitations of journals have been split into the first five and the last five years of the assessment period.

Figures II and III show the most frequently used keywords in PICMET publications for the years 2009-2013

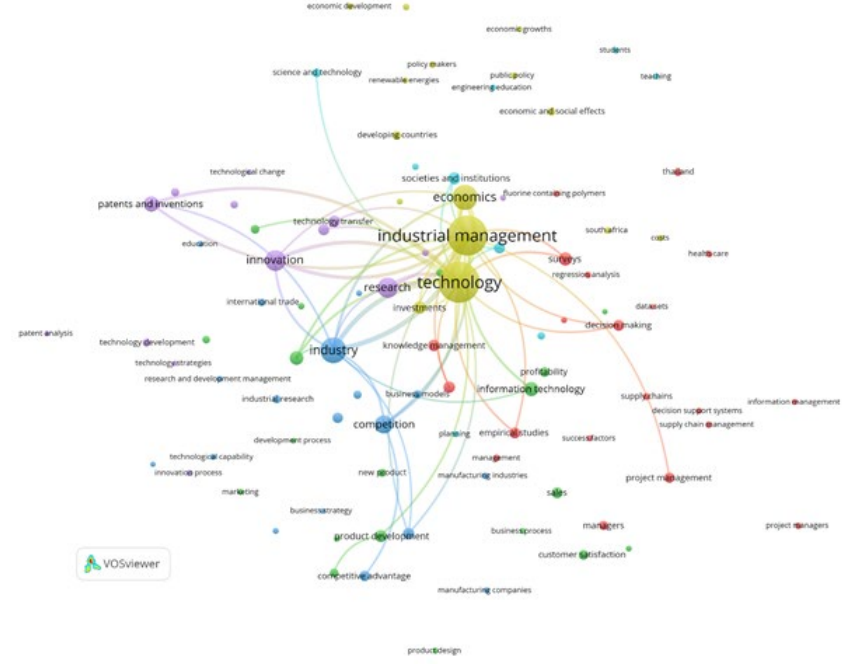

and 2014-2018 respectively.

FIGURE II: CO-OCCURRENCE OF KEYWORDS (2009-2013) THRESHOLD $=20 ;$ CONNECTIONS $=50$

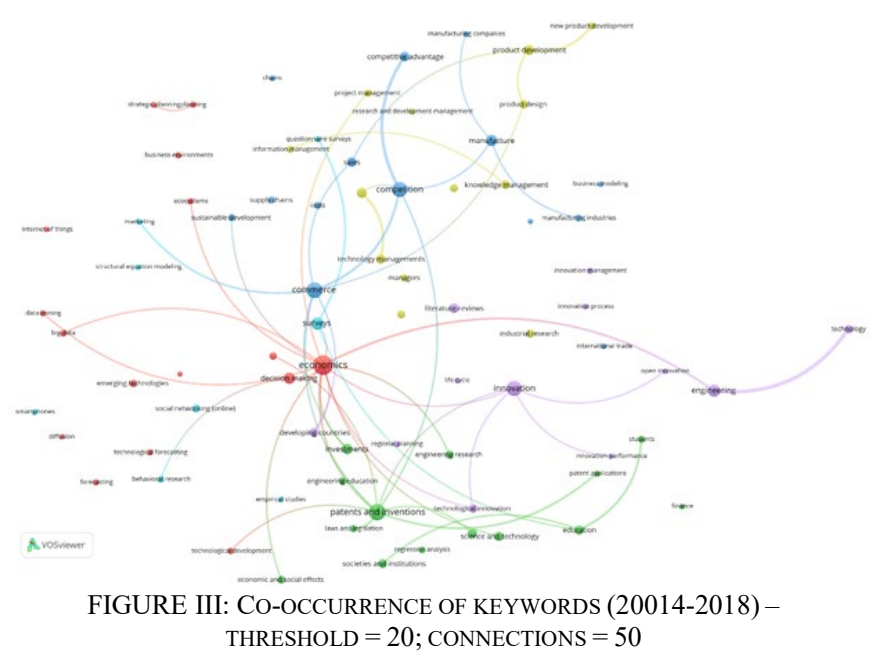

It appears that many of the key topics during the last 10 years, such as economics, competition, innovation, and patents and inventions remain active research areas. There are some other noteworthy developments though. The fields of industrial management and technology have experienced a decline in importance. On the other hand, the terms commerce, decision-making and surveys as a research method now receive more attention. It is also worth mentioning that the new term emerging technologies, while still not a central theme, has started to appear in PICMET publications in the last five years.

Comparing the current with the previous decade reveals an interesting change. In the period of 1997-2008, the top most frequently occurring words include from technology, management, development and innovation. Also included are the terms technology management, project management, knowledge management and information technology [6]. Even though technology and innovation keep their positions in the top 10 category, the popular themes change with the inclusion of keywords like economics, industry, competition and patents. And for the first time in a 20 years period, the top theme mentioned in PICMET papers became economics replacing technology which had been appearing on top of the list for 15 years.

Figures IV and V depict, how relevant journals connect to PICMET based on a co-citation analysis of PICMET publications considering a minimum threshold of 50 citations received and showing the 50 strongest links. This analysis is done for the first time for PICMET papers since it had not carried out in the previous two bibliometrics analysis $[5,6]$. 


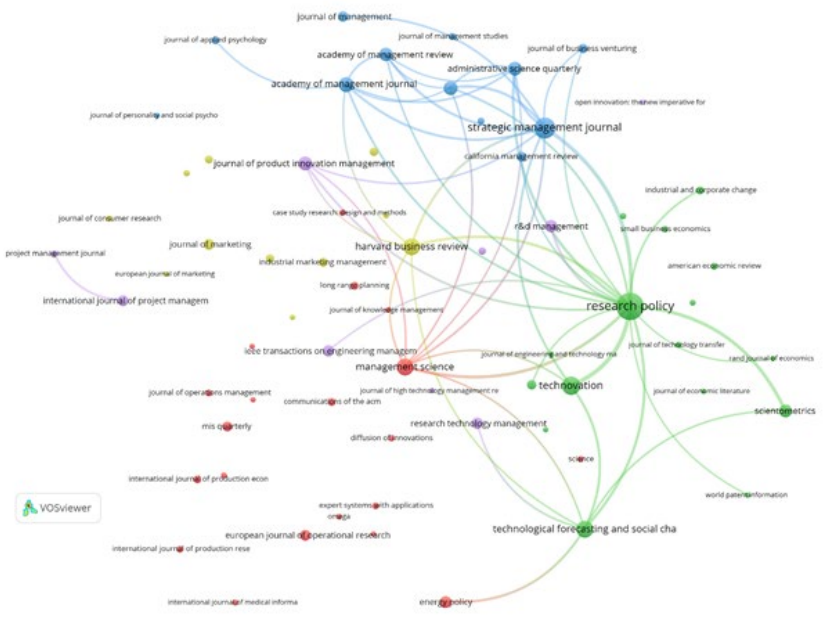

FIGURE IV: CO-CITATION OF JOURNALS (2009-2013)THRESHOLD $=50 ;$ CONNECTIONS $=50$

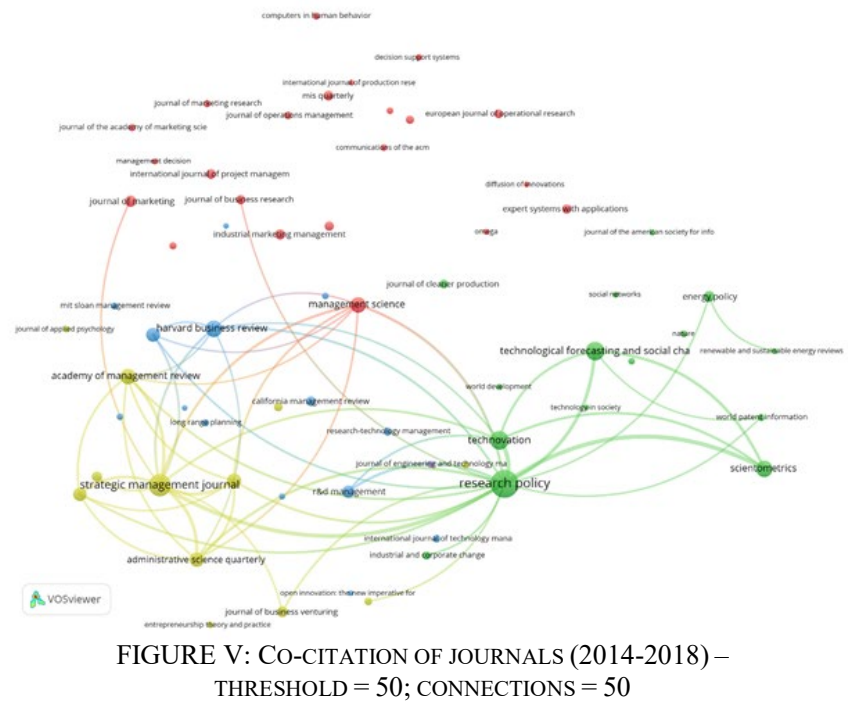

Research Policy, Technovation, Strategic Management Journal, Technological Forecasting and Social Change, Journal, Harvard Business Review and Management Science all remain among the most highly relevant journals throughout the last 10 years. This is not surprising given PICMET's focus on both management and technology.

A steep climb in influence can be observed for Scientometrics journal, which jumped to rank 5 in recent years (from rank 12 in 2009-2013), providing evidence for an increased focus of PICMET publications on quantitative research methods in recent years. The Journal of Product Innovation and Management on the other hand has experienced a slight drop in relevance from rank 7 (20092013) to 11 in recent years.

Overall, the analysis further confirms PICMET's broad, interdisciplinary publication profile, also citing journals from adjacent fields of research such as project management, marketing or energy policy.
Next, Figure VI visualizes the co-citation of authors of PICMET contributions. Results are shown using a threshold of 50 citations and the 100 most representative connections.

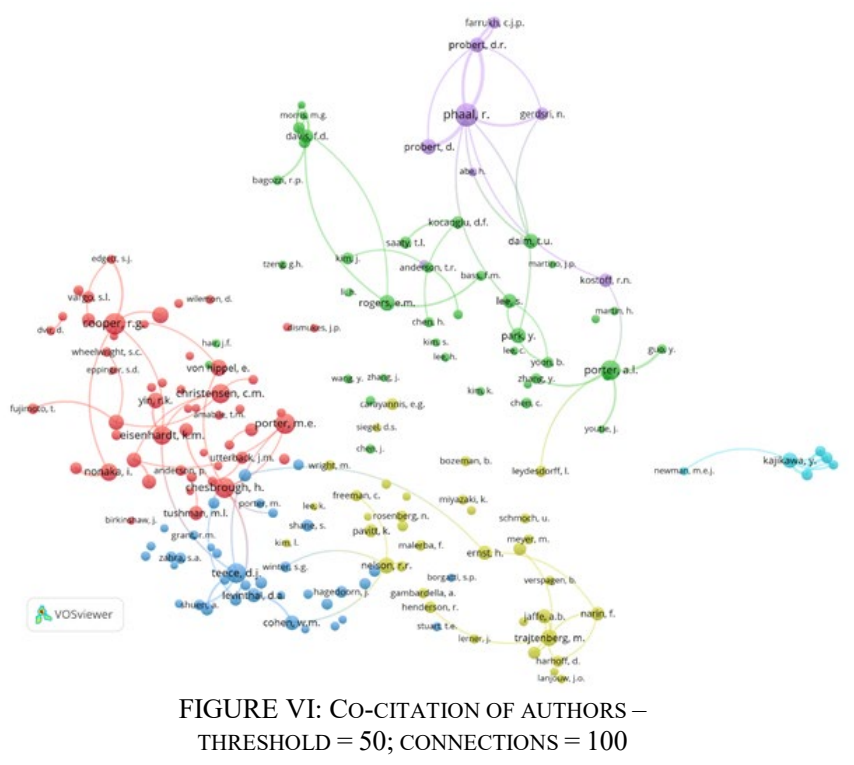

Results of the co-citation analysis show C. M. Christensen, M. E. Porter, H. Chesbrough, K. M. Eisenhardt, R. G. Cooper and R. Phaal to be among the most co-cited authors of PICMET in the last 10 years. Interestingly, these authors do not belong to the most productive contributors to PICMET. Given that fact, that PICMET itself is a conference and not an academic journal, this disparity is worth noting as apparently, the majority of PICMET contributions are not turned into journal publications which become relevant for future PICMET research. The top three most productive authors considering several bibliometric indicators such as the number of papers, the number of citations, the h-index, and the cites per paper are G. Schuh of RWTH Aachen in Germany, I. Sakata of University of Tokyo in Japan and H. N. $\mathrm{Su}$ of Nat Chung Hsing University in Japan. With G. Schuh from Germany and L. Pretorius of University Pretoria in South Africa being two exceptions, all other top 10 authors come from Japan, Taiwan and the U. S. reflecting PICMET's geographic scope in the Pacific region. Three PICMET authors, namely D. F. Kocaoglu, T.U. Daim and L. Pretorius, appear in the top 10 authors-list both in the last decade as well as in the period of 1997-2008 as shown by the previous study [6].

This is further confirmed looking at the most productive institutions contributing to PICMET (using the same bibliometric indicators). With the conference's home institution, the Portland State University in the U. S., leading the list, the top three are completed by the University of Pretoria in South Africa and the University of Tokyo in Japan. Noteworthy exceptions are, again, the RWTH Aachen in Germany and the Tampere University of Technology in Finland. These top institutions of PICMET authors seem to have stayed the same since 1997 [6]. 
Last, Figure VII presents the most productive countries contributing to PICMET by using a bibliographic coupling analysis with a threshold of 5 documents and 50 strongest bibliographic connections. It is worth noting that the analysis of countries represents the author affiliation at the time of publication in PICMET.

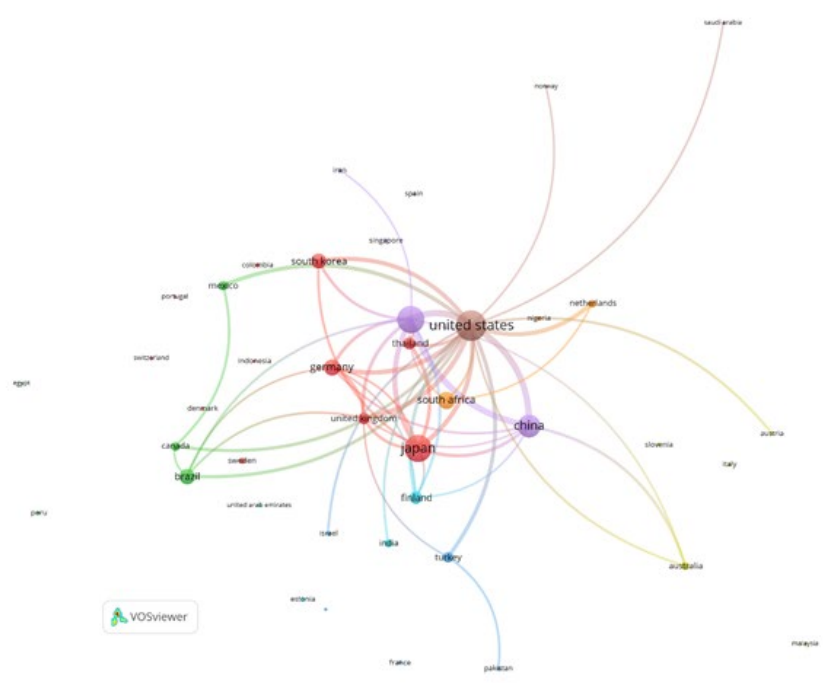

FIGURE VII: BIBLIOGRAPHIC COUPLING OF COUNTRIES THRESHOLD $=5 ;$ CONNECTIONS $=50$

The USA appears as the country with the highest number of published articles and the strongest bibliographic connections for PICMET. This is not surprising given both the country affiliation of PICMET itself and the country's size. Other big contributing countries, such as Japan, Germany, China, South Africa and Brazil, are again in line with results for biggest contributing authors and institutions. This was the case in the previous PICMET analysis too [6].

\section{DISCUSSION AND CONCLUDING REMARKS}

2019 marks the $30^{\text {th }}$ anniversary of PICMET. To celebrate this anniversary, this article presents a bibliometric review of PICMET's publications focusing on the last 10 years while at the same time compares the findings with the previously conducted PICMET reviews $[5,6]$. The considerations presented in this article are based on a broad set of bibliometric indicators and utilize a visualization tool which allows to analyse results by creating a map of bibliographic material. The research focusses on the identification of relevant keywords, journals, authors, institutions and countries and aims at offering a comprehensive picture of PICMET's positioning in its academic context.

Results seem to show that PICMET keeps providing a successful platform for academic exchange in the broad area of technology management. A slight shift in focus towards more quantitative research methodologies as well as emerging technologies and economics as research subjects seem to be in line with wider trends in academic methodology and hot topics in the academic and professional communities.
PICMET, while emphasizing its focus as a platform for the Pacific region, hosts participants from a wide range of institutions and countries.

While this article focuses on the development of PICMET over the last 10 years, a more extensive research project could include the overall timeline of PICMET's evolution from 1989 until today in order to identify trends developing more slowly. More specific analyses can also include identification of bibliometric factors on the level of individual articles and an analysis of citations of PICMET articles in other publications.

\section{REFERENCES}

[1] Allen, T. (2004). 50 years of engineering management through the lens of the IEEE Transactions. IEEE Transactions on Engineering Management 51 (4), 391-395.

[2] Roberts, E.B. (2004). A perspective on 50 years of the engineering management field. IEEE Transactions on Engineering Management 51 (4), 398-403.

[3] Cetindamar, D., Wasti, S.N., Ansal, H. \& Beyhan, B. (2009). Does technology management research diverge or converge in developing and developed countries?, Technovation, 29 (1), 45-58.

[4] Gudanowska, A. E. (2017). A Map of Current Research Trends within Technology Management in the Light of Selected Litreature, Management and Production Engineering Review, 8 (1): 78-88.

[5] Porter, A. L., Watts, R. J., and Anderson, T. R. (2003). Mining PICMET: 1997-2003 Papers Help you Track Management of Technology Developments, PICMET 03.

[6] Kwakkel, J., Cunningham, S. W., and Anderson, T. R., (2009). Remining PICMET, PICMET 09.

[7] Porter, A. L., Schoeneck, D. J., Anderson, T. R. (2012). PICMET Empirically: Tracking 14 Management of Technology Topics, PICMET 12.

[8] Broadus, R.N. (1987). Toward a definition of "Bibliometrics". Scientometrics, 12(5-6), 373-379.

[9] Pritchard, A. (1969). Statistical bibliography or bibliometrics? J of Documentation, 25, 348-349.

[10] Bar-llan, J. (2008). Informetrics at the beginning of the 21 century- a review. J of Informetrics, 2(1), 1-52.

[11] Gaviria-Marín, M., Merigó, J.M., Popa, S. (2018). Twenty years of the Journal of Knowledge Management: A bibliometric analysis, J of Knowledge Management, 22, 1655-1687.

[12] Merigó, J.M., Pedrycz, W., Weber, R., \& de la Sotta, C. (2018). Fifty years of Information Sciences: A bibliometric overview. Information Sciences, $432,245-268$.

[13] Cancino, C., Merigó, J.M., Coronado, F., Dessouky, Y., \& Dessouky, M. (2017). Forty years of Computers \& Industrial Engineering: A bibliometric analysis. Computers \& Industrial Engineering, 113, 614-629.

[14] Ding, Y., Rousseau, R., \& Wolfram, D. (2014). Measuring scholarly impact: Methods and practice, Springer, Switzerland.

[15] Laengle, S., Merigó, J.M., Miranda, J., Slowinski, R., Bomze, I., Borgonovo, E., Dyson, R.G., Oliveira, J.F., \& Teunter, R. (2017). Forty years of the European Journal of Operational Research: A bibliometric overview. European J of Operational Research, 262(3), 803-816.

[16] Martínez-López, F.J., Merigó, J.M., Valenzuela, L., \& Nicolás, C. (2018) Fifty years of the European Journal of Marketing: A bibliometric analysis. European J of Marketing, 52(1-2), 439-468.

[17] Merigó, J.M., Mas-Tur, A., Roig-Tierno, N., \& Ribeiro-Soriano, D. (2015). A bibliometric overview of the Journal of Business Research between 1973 and 2014. J of Business Research, 68(12), 2645-2653. 
[18] Cobo, M.J., Lopez-Herrera, A.G., Herrera-Viedma, E., \& Herrera, F. (2011). Science mapping software tools: Review, analysis and cooperative study among tools. J of the American Society for Information Science and Technology, 62(7), 1382-1402.

[19] Van Eck, N.J., \& Waltman, L. (2010). Software survey: VOSviewer, a computer program for bibliometric mapping. Scientometrics, 84(2), 523-538.

[20] Small, H. (1973). Co-citation in the scientific literature: A new measure of the relationship between two documents. J of the American Society for Information Science, 24, 265-269.

[21] Kessler, M.M. (1963). Bibliographic coupling between scientific papers. American Documentation, 14(1), 10-25.

[22] Tur-Porcar, A., Mas-Tur, A., Merigó, J.M., Roig-Tierno, N., \& Watt, J.

(2018). A bibliometric history of the Journal of Psychology between 1936 and 2015. J of Psychology, 152, 199-225.

[23] Blanco-Mesa, F., Merigó, J.M., Gil-Lafuente, A.M. (2017). Fuzzy decision making: A bibliometric-based review, J of Intelligent \& Fuzzy Systems, 32, 2033-2050.

[24] Valenzuela, L., Merigó, J.M., Johnston, W., Nicolás, C. \& Jaramillo, F. (2017). Thirty years of the Journal of Business \& Industrial Marketing: A bibliometric analysis. J of Business \& Industrial Marketing, 32(1), 1-18.

[25] Modak, N.M., Merigó, J.M., Weber, R., Manzor, F., \& Ortuzar, J.D (2019). Fifty years of Transportation Research journals: A bibliometric overview. Transportation Research Part A, 120, 188-223. 